\title{
Importancia de la medición del Nivel de Servicio o Fill Rate en la Logística Moderna
}

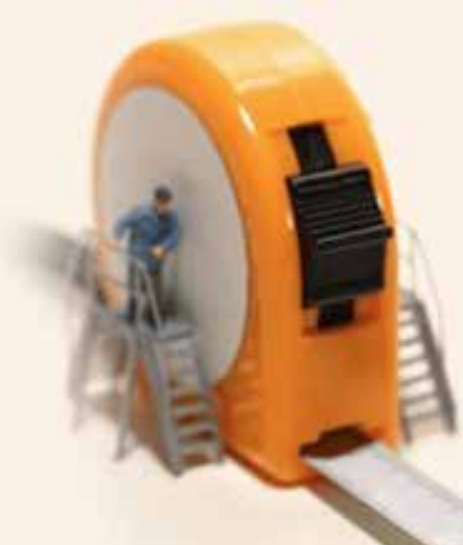

Por. Ing. Jorge Arnoldo Valencia Granados

Director de Portal Logístico y Consultor en Logística, Comercio Internacional

y Sistemas Estratégicos de Información· jorge.valencia@portallogistico.com

\begin{abstract}
RESUMEN
Las empresas necesitan saber cuál es su nivel de desempeño logístico para poder impulsar planes de mejora. A menos que el indicador logístico del Nivel de Servicio sea incluido en el análisis, difícilmente se podrá establecer si se han obtenido resultados positivos.
\end{abstract}

Uno de los problemas más críticos es que la mayoría de las empresas no lo calculan o bien lo calculan con datos poco confiables. El presente artículo señala la importancia de este indicador logístico y ofrece alternativas para su mejora en el tiempo.

PALABRAS CLAVE: Logística, Indicador, Fill Rate, Nivel de Servicio, Inventarios.

\section{INTRODUCCIÓN}

A diferencia de otras disciplinas, en logística el concepto de Nivel de Servicio (NS) o Fill Rate (FR) tiene una connotación más numérica, más estadística y mucho más precisa. Tradicionalmente, se puede valorar el nivel de servicio como excelente, bueno, regular, malo o pésimo. Pero eso no es suficiente en logística.

El Nivel de Servicio posibilita medir la eficiencia con el que el sistema logístico sirve al mercado. Es también útil para medir los efectos de los proyectos e inversiones logísticas. Todo proyecto debe mejorar este indicador, pues reflejará mayores ingresos y mejor aprovechamiento de recursos.

\section{EL NIVEL DE SERVICIO COMO INTEGRADOR DE CAPACIDADES}

A pesar de que el Nivel de Servicio es uno de los indicadores claves en el cumplimiento de la logística en la empresa, el término resulta confuso en la práctica. Puede calcularse de diferentes formas, siendo todas ellas válidas. Representa básicamente la fracción de los pedidos, del stock, de las líneas o renglones que la empresa es capaz de satisfacer en base al requerimiento o pedido de sus clientes.

En su diccionario de logística, Mora (2011:14) subraya que el Nivel de Servicios es una "medida deseada de satisfacción de la demanda (usualmente expresada como un porcentaje ) a través del inventario o por el actual programa de producción justo a tiempo para cumplir con las fechas y cantidades solicitadas por los clientes".

Ampliando la definición, lo que no puede entregarse en forma inmediata no se considera en el cálculo. De esta forma, se puede considerar que:

$$
P C=P E+B O+V P(1)
$$

Donde PC es el pedido del cliente; PE pedido entregado; BO back orders y VP ventas perdidas.

Al dividir todo entre el pedido del cliente, y mostrarlo porcentualmente, se tiene:

$$
100 \%=\% N S+\% B O+\% \operatorname{VP}(2)
$$

Donde \%NS es el Nivel de Servicio o Fill Rate; \% BO es el porcentaje de back orders en relación el pedido y \% VP es el porcentaje de ventas perdidas en relación con los pedidos recibidos. 
Un Nivel de Servicio del 70\% puede representar entonces:

- Que sólo se entregó el $70 \%$ de los ítems solicitados. Por ejemplo, si se pidieron 200, sólo se entregaron 140 ítems. Estas son cifras globales, aunque mezclan diferentes tipos de producto con un mismo peso relativo.

- Que sólo se entregó completo el $70 \%$ del total de los pedidos recibidos. Por ejemplo, si un cliente realiza 10 pedidos, sólo se entregaron 7 completos. Esta forma de cálculo nos muestra qué tanto se le cumple al cliente en una sola entrega. Normalmente, los clientes requieren recibir todo el producto para cumplir también sus obligaciones con sus clientes y también como parte del proceso de recepción establecido. De no hacerlo, se incurren en multas.

- Que sólo se entregaron completas el $70 \%$ de las líneas de producto o renglones. Si, por ejemplo, si cada uno de los 10 pedidos tiene 7 ítems (70 renglones en total) y sólo despachamos completos - lo solicitado vrs lo entregado - 49 líneas. Una línea representa un traslado del operario de almacén a la ubicación donde debiera estar el producto. Es, pues, representativo de la eficiencia con el que el operador recolecta el pedido, una medida de su productividad.

Una empresa comercial, por ejemplo, puede recibir un pedido por varios ítems y, sin embargo, sólo ser capaz de entregar una fracción de este. No significa necesariamente que la empresa brinde un mal servicio. Puede también realizar negociaciones especiales para que el cliente acepte recibir posteriormente otra fracción del pedido que, por no contar con disponibilidad inmediata, no se entrega y queda en "Back Order". Finalmente, las ventas perdidas representan el complemento del nivel de servicio y del Back Order y son la fracción del pedido que el cliente rechaza de su pedido original en virtud de su urgencia y de no poder esperar a que llegue un nuevo pedido para él. Todos juntos representan el $100 \%$ del pedido y el fenómeno se da igual en ventas comerciales que en industriales.
En el ejemplo numérico de la fig. 1, se muestran los pedidos recibidos por una librería para un cliente en particular. Se tienen siete pedidos analizados con su correspondiente nivel de servicio basado en stock, pedidos y líneas.

Los niveles de servicio pueden calcularse para clientes específicos, períodos, proveedores, marcas, categorías, canales de distribución, etc.

Es conveniente definir si el análisis se hará en base a unidades o con cifras monetarias. Ello dependerá del acceso a dichos datos.

Fig. 1

Análisis nivel de servicio librería para un cliente en particular.

\begin{tabular}{|c|c|c|c|c|}
\hline PEDIDOS & SOLICITADO & DESPACHADO & UNEAS & $\begin{array}{l}\text { UNEA } \\
\text { COMPLETA }\end{array}$ \\
\hline PEDIDO 1 & & & 3 & \\
\hline Mercadeo & 2 & 2 & & 1 \\
\hline Contabilidad & 4 & 0 & & \\
\hline Personal & 1 & 1 & & 1 \\
\hline PEDIDO 2 & & & 3 & \\
\hline Finanzas & 2 & 2 & & 1 \\
\hline Personal & 1 & 1 & & 1 \\
\hline Contabilidad & 1 & 0 & & \\
\hline PEDIDO 3 & & & 3 & \\
\hline Personal & 1 & 1 & & 1 \\
\hline Termodinámica & 2 & 1 & & \\
\hline Cálculo & 4 & 1 & & \\
\hline PEDIDO 4 & & & 2 & \\
\hline Mercadeo & 4 & 3 & & \\
\hline Logistica & 1 & 1 & & 1 \\
\hline PEDIDO 5 & & & 1 & \\
\hline Finanzas & 10 & 0 & & \\
\hline PEDIDO 6 & & & 2 & \\
\hline $\begin{array}{l}\text { Métodos } \\
\text { cuantitativos }\end{array}$ & 5 & 5 & & 1 \\
\hline Contabilidad & 4 & 4 & & 1 \\
\hline PEDIDO 7 & & & 3 & \\
\hline Contabilidad & 4 & 2 & & \\
\hline Finanzas & 4 & 4 & & 1 \\
\hline \multirow[t]{7}{*}{ Logistica } & 5 & 2 & & \\
\hline & 55 & 30 & 17 & 9 \\
\hline & \multicolumn{4}{|c|}{ Cálculo NS en base a unidades } \\
\hline & N5 (a nivel stock) & $30 / 55$ & $54.55 \%$ & \\
\hline & NS (a nivel pedido) & $1 / 7$ & $14.29 \%$ & \\
\hline & N5 (a nivel lineas) & $9 / 17$ & $52.94 \%$ & \\
\hline & \multicolumn{4}{|c|}{$\begin{array}{l}\text { NS a nivel pedido y lineas se estiman en base } \\
\text { a pedidos y lineas completas entregadas. }\end{array}$} \\
\hline
\end{tabular}

Fuente: Elaboración Propia 


\section{UNIDAD DE MEDIDA O EXPRESIÓN}

Los Niveles de Servicio son razones porcentuales. No cuentan con unidad de medida y pueden calcularse en base a unidades o términos monetarios. En nuestro medio, la información con la que se cuenta es limitada en las áreas logísticas y, en numerosas ocasiones, no hay datos de costos. Se puede calcular de cualquier forma, tomando en cuenta que los resultados no serán iguales, puesto que un ítem que tiene 100 unidades de stock y que vale un dólar cada uno, no tendrá el mismo peso que 100 unidades de otro ítem que vale mil dólares cada uno. No es lo mismo.

De igual forma, los Niveles de Servicio podrán representarse por período, por producto, por categoría, por sucursal o tienda, por cliente, por proveedor, por marca, etc. Deberá estipularse en un manual de indicadores qué es lo que se entenderá por Nivel de Servicio y su procedimiento de cálculo.

\section{NIVEL DE SERVICIO IDEAL}

¿Cuálesentonceselmejorniveldeservicio? Idealmente, el Nivel de Servicio para un artículo debería ser el 100 $\%$. Pero hay algunas consideraciones que deberán tomarse en cuenta para no errar en el análisis. La primera tiene que ver con que si la empresa considera existencias para el artículo solicitado o si sólo se pide contra pedido. La siguiente es la etapa del ciclo de vida del producto, pues hay ítems que la empresa ha decidido no comercializar más y, en consecuencia, sólo espera agotar existencias. Y, finalmente, una consideración económica importantísima: una empresa puede ofrecer $100 \%$ de Nivel de Servicio y, aun así, exhibir pérdidas puesto que resulta muy caro tener de todo, para todos, en las cantidades que todos desean. El nivel de inventario deberá compararse con la utilidad resultante de mantener tal o cual política de inventario.

Los diferentes productos y categorías de productos que maneje la empresa tendrán diferentes Niveles de Servicios. En unos será de alto impacto y en otros no tendrá una contribución especial. Pueden utilizarse criterios como ABC, el 80/20 de Pareto, matriz de Kraljic, etc

Es necesario tener un panorama claro de cómo utilizar el Nivel de Servicio para la mejora de la logística empresarial. En varias ocasiones las empresas no calculan el este indicador pues es un proceso complicado, no hay tiempo o recurso humano para hacerlo, etc. Estas objeciones desaparecen cuando ven los beneficios potenciales de administrar este indicador, así como las implicaciones que tiene para la administración del negocio. Tómese el siguiente gráfico que ilustra, día por día, las ventas perdidas, a nivel precio de venta, en una empresa.

Fig. 2

Ventas perdidas por día

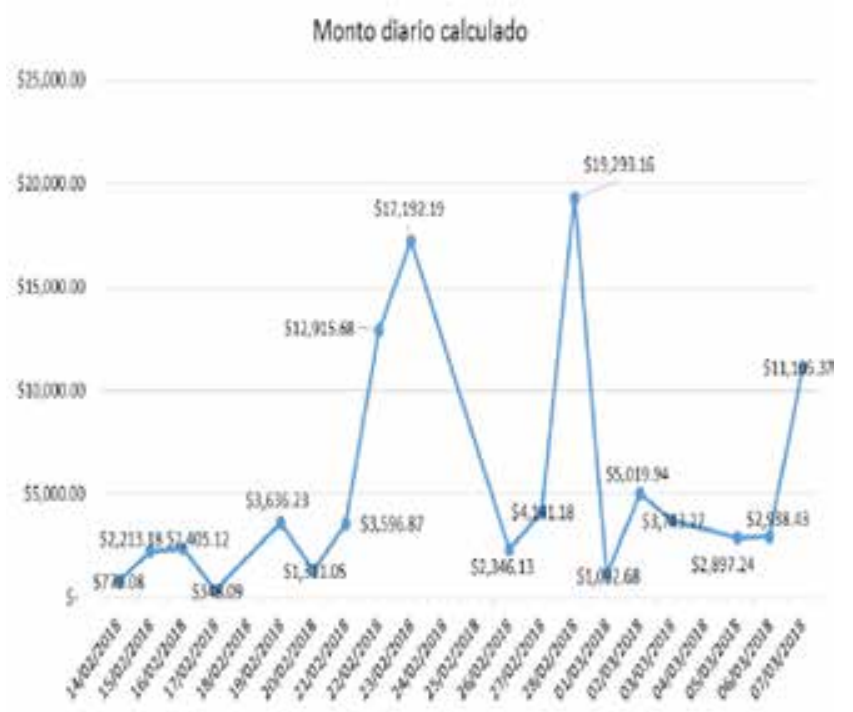

Fuente: Elaboración Propia

Cuando algo como esto sucede, los esfuerzos, de marketing y ventas principalmente, no se ven recompensados, pues no se venden artículos que el cliente solicitó. En este ejemplo, se están perdiendo $\$ 5,000$ diarios, en promedio, por no contar con un adecuado plan de reposición de inventarios y ni con los niveles óptimos que demandaba el mercado.

Al medir las ventas perdidas y sumarle las ventas totales facturadas se obtendrá el monto de los pedidos. A partir de allí se podrá obtener el porcentaje de nivel de servicio o, en su defecto, el porcentaje de ventas perdidas.

Otra situación muy común ocurre cuando no se ingresan al sistema los datos completos del pedido, sino que, a partir del pedido, se ingresan sólo los datos de lo que se le facturó al cliente. De esta forma, no es posible calcular fácilmente desde el sistema informático el Nivel de Servicio y posteriormente debe hacerse manualmente utilizando un muestreo o bien revisando pedido contra factura diariamente. 
El indicador de los Niveles de Servicio puede ser establecido como política por la dirección de la empresa. En algunos casos, se asocia a un tiempo de respuesta. Por ejemplo: 80 \% de Nivel de Servicio en 24 horas. Puede resultar difícil su medición objetiva.

\section{CONSECUENCIAS DE UN POBRE NIVEL DE SERVICIO}

Ciertamente, este indicador logístico afecta a la empresa proveedora de muchas formas:

1. Recibe una mala evaluación de su cliente

2. Recibe penalizaciones

3. Se le pierde la confianza

4. Se le solicitan menos productos en el futuro

5. Se pierden clientes

Los encargados del área de compras deberían medir constantemente este indicador para tomar decisiones sobre la evaluación de sus proveedores

\section{RECOMENDACIONES PARA}

MEJORAR EL NIVEL DE SERVICIO

Algunas estrategias genéricas que pueden contribuir a mejorar el Nivel de Servicio son:

- Aumentar la capacidad de producción para productos de alta demanda

- Reducir el número de productos dañados y devoluciones

- Reducir los tiempos de importación de productos terminados

- Aumentar la duración de los productos perecederos con un almacenamiento adecuado

- Utilizar técnicas de pronóstico con datos confiables

- Mejorar la confiabilidad de sus envíos

- Comunicación más efectiva con clientes y proveedores
Una de las trampas en las que se suele caer cuando se trata de mejorar el Nivel de Servicio es la de considerar que éste sólo puede optimizarse mediante compras mayores de inventario. Se presume que no se vende porque no se cuenta con stock suficiente y que aumentando la cantidad de producto la situación se resuelve.

En cierta forma, esa suposición es correcta, aunque no completamente. Primero, porque pueden existir graves deficiencias en la exactitud del inventario que se maneja. Y, segundo, porque puede ser posible, mediante un acercamiento colaborativo entre proveedores y clientes, estimar mejor la demanda futura y no pedir solo por pedir basándose en puras corazonadas. El proveedor puede recomendar productos que, de otra forma, no se hubieran considerado y ayudar a estimar valores mínimos y máximos para el inventario (Estrategias VMI y CPFR). El cliente, por su parte, puede dar información valiosa sobre su programa de pedidos para que el aprovisionamiento funcione menos errático. La logística colaborativa entre proveedores, empresas y clientes es la clave para mejorar sustancialmente el Nivel de Servicio en toda la cadena.

\section{CONCLUSIONES}

1. El Nivel de Servicio o Fill Rate es uno de los indicadores claves de desempeño que permite evaluar la forma en que la empresa atiende a sus clientes.

2. El Nivel de Servicio puede medirse de diferentes maneras según sea el alcance del análisis que se pretenda realizar.

3. El Nivel de Servicio no puede quedar ausente de cualquier propuesta de mejora logística. Resulta indispensable relacionarlo con los niveles de inventario, políticas con clientes y proveedores.

4. El Nivel de Servicio puede ser mejorado de muchas maneras sin incluir un incremento sustancial del stock. 